\title{
НОВЫЕ ЭКОНОМИЧЕСКИЕ МОДЕЛИ ТУРБИЗНЕСА В ПЕРИОД КОРОНАВИРУСНЫХ ОГРАНИЧЕНИЙ. ОПЫТ И ОСНОВНЫЕ ТЕНДЕНЦИИ
}

\author{
(C) 2021 Ахремчик Денис Витальевич \\ аспирант 2-го курса \\ Международный инновационный университет, Россия, Москва \\ E-mail:ahremchik1993@mail.ru
}

В данной статье обоснована актуальность применения новых экономических моделей при ведении туристического бизнеса в период ограничений, связанных с пандемией COVID-19. Помимо этого, определены методология и методы, с помощью которых было проведено исследование. В представленной статье использовались комплексный, системно-структурный анализ, а также метод сравнения, применение которого помогло получить выводы в процессе анализа динамики статистических данных туристической отрасли за исследуемый период. Применение выбранной методологии проводилось с помощью использования различных информационных источников, а также специальной литературы, которая отражает сущность поставленной темы исследования. В работе проведено исследование влияния новой коронавирусной инфекции на туристический бизнес, как на территории России, так и в мировом пространстве, изучен новый подход к ведению такого бизнеса, использование цифровых технологий в туризме с целью повышения конкурентоспособности, обеспечения устойчивого развития туристической отрасли в период влияния COVID-19, а также после него. Представлена аналитическая информация, отражающая обстановку в экономике в связи с пандемией во время введения ограничительных мер и после режима самоизоляции. Изучено влияние коронавируса на получение доходов туристическими компаниями, их убытками, а также представлено сравнение полученной совокупной прибыли в период 2018-2020 гг. В статье рассмотрены наиболее популярные тенденции и опыт туристических компаний, а также приведены примеры результатов цифровизации туристической отрасли в мире. Сделаны выводы на основе проведенного исследования, сущность которых заключается в необходимости применения новых экономических моделей в туристическом бизнесе, так как современный мир претерпел изменения, которые должны быть обязательно учтены для успешного бизнеса в сфере туризма.

Ключевые слова: туризм, туристическая отрасль, COVID-19, пандемия, экономическая модель, цифровизация

В настоящий момент весь мир переживает нелегкие времена, связанные с распространением новой коронавирусной инфекции COVID-19, начало которой отмечается в декабре 2019 года. Несмотря на то, что появление нового вируса зафиксировано в Китае, на данный момент он уже охватил территорию всего мира, каждое государство столкнулось с этой проблемой, что существенно отразилось на экономике стран в негативном ключе. Особенно заметные последствия наблюдаются в отдельных сферах экономики, являющихся структурными элементами национальной экономики. Одной из таких отраслей в России является туристический бизнес, который, несмотря на кризисную ситуацию, связанную с введением ограничительных мер из-за пандемии новой коронавирусной инфекции COVID-19, имеет достаточно высокую попу- лярность. Туристический бизнес является одной из отраслей экономики, которые в наибольшей степени пострадали под влиянием разразившегося коронавируса [1]. Экономика в целом нуждается в большой поддержке со стороны государства, которую она получила в самом начале, когда органы государственной власти были вынуждены ввести комплекс карантинных мер и мероприятий [2], однако это продолжилось не долго, а часть ограничений в связи с распространением COVID-19 общество наблюдает и в настоящий момент, что сильно отражается на туристическом бизнесе. То есть с появлением новой коронавирусной инфекции совокупный спрос на многие виды продукции и услуг сократился, выросла доля безработных, поэтому хозяйствующие субъекты были вынуждены внедрять инновации, использовать новые модели 
ведения бизнеса в целях поддержки и развития своей деятельности в таких сложных эпидемиологических условиях. Компании, функционирующие в сфере туризма, не являются исключением. В связи с тем, что туризм во время пандемии пострадал в наибольшей степени, поиск новых моделей ведения бизнеса и повышения спроса на услуги обусловила актуальность данного исследования.

В целях проведения исследования была использована научная и эмпирическая база в области туристического бизнеса и влияния на нее коронавируса. Основу написания данной работы составили статистические данные, отраженные на официальных сайтах Федеральной службы государственной статистики и Всемирной туристской организации UNWTO. Также большой вклад в исследование внесли аналитические статьи А.С. Сагынбековой и О.А. Куликова. В их работах представлена актуальная информация в области взаимосвязи важных составляющих нашего исследования, а именно туризма, COVID-19 и нового подхода к ведению бизнеса в условиях пандемии коронавируса.

Еще одной работой, послужившей методологической основой исследования, является статья А.А. Курочкиной, А.С.Лящук и С.А. Смирновой «Digital-маркетинг в гостиничном бизнесе». Данный источник был взят за основу благодаря наглядно представленным результатам исследования digital-маркетинга гостиничного бизнеса, как одной и составляющих туристической отрасли, его использования в процессе расширения своей аудитории клиентов. Такая информационная база послужила достойным ресурсом для проведения собственного исследования цифровизации для туристической отрасли мировой экономики. Также важным моментом при выборе методологической основы выступало наличие в работе авторов анализа преимуществ и недостатков тех или иных методов исследования.

Каждое исследование, наше не является исключением, проводится с помощью использования своего методологического аппарата, представляющего собой ту совокупность научных работ и методов исследования, которая легла в основу написания статьи. Методологические основы исследования подбираются в зависимости от темы исследования.

Объектом исследования данной работы выступает новая экономическая модель в туристическом бизнесе во время пандемии COVID-19.
Исследование проводилось с помощью комплексного и системно-структурного анализа, метода сравнения. Использование первого метода обусловлено изучением туристической отрасли в период коронавирусных ограничений в целом, второго метода - детальным исследованием особенностей новой экономической модели туриндустрии в современном мире. Метод сравнения использовался для получения выводов по динамике данных туристической отрасли за период 2018-2020 гг.

Туристический бизнес в настоящее время имеет большое значение для населения не только нашей страны, но и всего мира. Большинство людей в качестве отдыха используют поездки и путешествия, которые могут совершаться, как внутри страны, так и за границу. Все это относится к области туризма. Настоящее время, как нами упоминалось ранее, характеризуется распространением пандемии новой коронавирусной инфекции COVID-19 в мировом пространстве, что затрудняет оказание услуг исследуемой отрасли, кроме того создает угрозу для жизни и здоровья граждан, что, в свою очередь, накладывает дополнительные трудности для ведения туристического бизнеса в данный момент. Все это в совокупности обуславливает поиск новых экономических моделей для туристического бизнеса, которые помогают оставаться рентабельной деятельность во время пандемии COVID-19.

Как было выяснено, сильное негативное влияние коронавирусная инфекция оказала, конечно, на туризм, что доказывают статистические данные [3]. Только за 2020 год мировая экономика недополучила прибыль от туризма в размере 40-50 млрд. долл. США. За последние два десятка лет кризис, вызванный COVID-19, стал третьим масштабным явлением, принесшим негативное воздействие на экономику и отрицательную динамику в области получения доходов от туристических услуг примерно на 20-30\% [4], что превышает значения снижения от предыдущих кризисов в сфере туризма в несколько раз [5].

Российский туризм в 2020 году от иностранных туристов получил 3212,34 млн. долл. США, что меньше предыдущего аналогичного периода на $70,70 \%$. Такая же динамика наблюдается и в отношении деловых поездок, их снижение составило $56,90 \%$, от этой категории туристов было получено 2046,46 млн. долл. Но в большей степени влияние пандемии отразилось на индивидуальных поездках, прибыль от которых со- 
ставила всего 1 165,85 млн. долл., что ниже представленного показателя в 2019 году на 81,20\% [1]. На рисунке 1 наглядно представим динамику доходов от разных направлений туризма за период 2019-2020 гг.

Согласно информации, представленной на рисунке 1 , можно заметить, что в отношении общего показателя въездного туризма, а также его составляющих (индивидуальных и деловых поездок) наблюдается резко негативная динамика, связанная с введением ограничительных мер в связи с распространением новой коронавирусной инфекции COVID-19 [4].

Влияние пандемии на туристическую отрасль экономики отразилось не только в значительном снижении прибыли, но и в сокращении количества компаний, функционирующих в туриндустрии, сведения о которых содержатся в
Едином федеральном реестре туроператоров (ЕФР). Согласно ЕФР число туристических организаций за период 2019-2020 гг. сократилось на $6,83 \%$, что означает ликвидацию 315 компаний за два года [7]. Если проводить аналогию с 2018 годом, то можно наблюдать не такой большой разрыв: за период 2018-2020 гг. число туроператоров снизилось на 3\%, или на 128 компаний. Такая динамика говорит о том, что за период 2018-2019 гг. наблюдалась исключительно положительная тенденция в отношении общего числа туроператоров благодаря росту числа компаний, деятельность которых акцентируется на международных и выездных турах, количество которых резко сократилось за 2019-2020 гг. в связи с распространением COVID-19. Динамика количества туроператоров более наглядно представлена на рисунке 2.

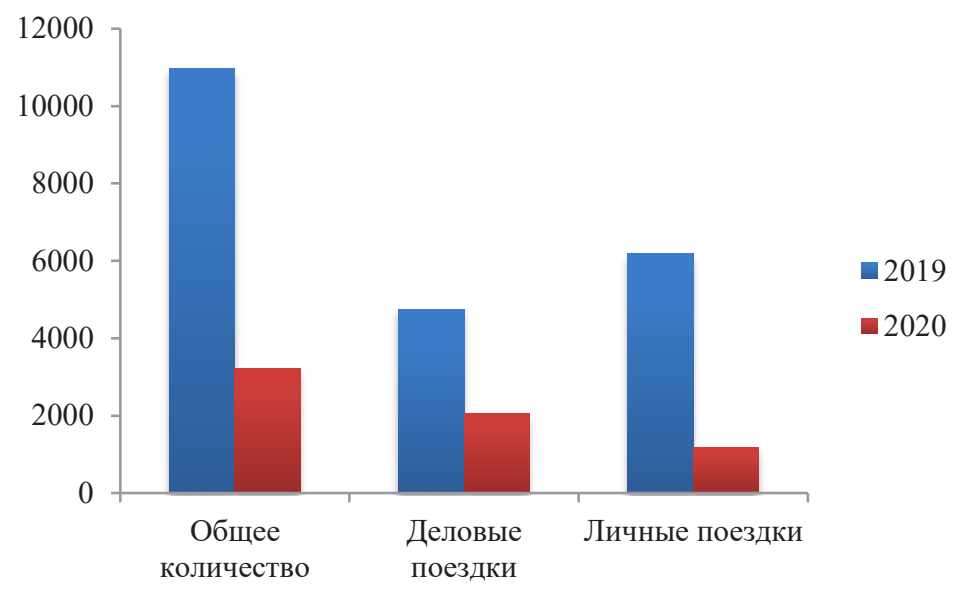

Puc. 1. Динамика прибыли от въездных поездок в Россию, млн. долл. США [1]

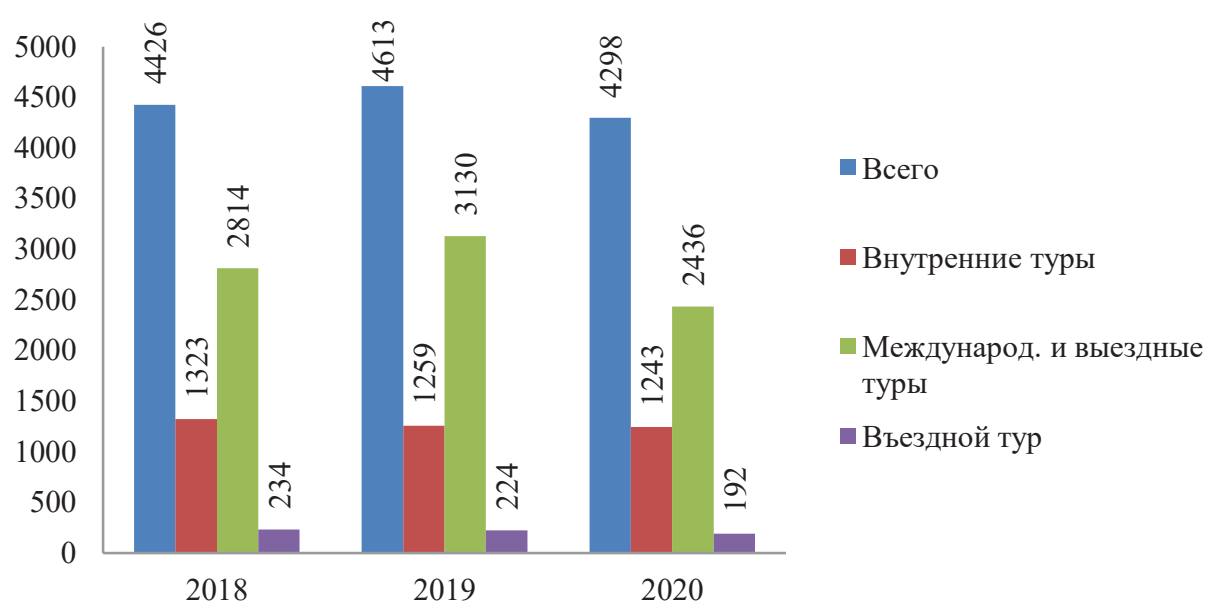

Puc. 2. Динамика количества туроператоров согласно ЕФР, ед. Источник: составлено автором на основе [7] 
Такая кризисная обстановка вынудила руководство туристических компаний к принятию сложных решений по оптимизации существующих бизнес-моделей, поиску путей сокращения издержек, а также к развитию новых направлений бизнеса [8]. В первую очередь, это было мотивировано введением ограничительных мер, переводом на самоизоляцию работников практически всех сфер экономики, согласно которым сотрудники большей части предприятий страны были вынуждены оставаться дома. Но большинство компаний, среди которых находятся и туристические организации, не могли приостановить полностью свою деятельность, поэтому множество из них было ликвидировано, либо сокращен в большей части кадровый состав [9]. Но остались и те, которые предприняли попытки по внедрению новых экономических моделей ведения бизнеса, основные направления которых были отражены в докладе OOH «COVID-19 и трансформация туризма». Эти направления представим далее:

1. Смягчение социально-экономических последствий;

2. Повышение конкурентоспособности и устойчивости;

3. Цифровизация туристической отрасли (диджитализация);

4. Содействие устойчивому развитию с помощью повышения уровня экологизации, осознанного развития;

5. Координация и партнерство для трансформации туриндустрии и ее устойчивого развития [10].

Перечисленные тенденции являются основой для новых экономических моделей ведения туристического бизнеса, которые помогут восстановить и преобразовать исследуемую отрасль мировой экономики.

Как показывает научный опыт, получение импульса для дальнейшего развития любой области жизнедеятельности человечества происходит именно под влиянием кризисных ситуаций, вызванных различными причинами. Так, кризис, который имеет место быть в связи с распространением новой коронавирусной инфекции, способствовал трансформации туристической отрасли во всем мировом пространстве. В первую очередь, это связано с применением цифровых технологий в хозяйственной деятельности посредством использования сети «Интернет». Это сейчас является особенно популярным, так как ее использование в процессе осуществления экономической деятельности представляет собой одну из составляющих государственной программы по цифровизации экономики России [11]. Масштабное внедрение и использование цифровых технологий на территории Российской Федерации обусловлено ориентированностью общества и экономики на скорость, быстрое реагирование на любые изменения, и цифровизация, непосредственно, позволяет ускорять большинство процессов жизнедеятельности граждан, функционирования хозяйствующих субъектов и осуществления ими их экономической деятельности [12]. Что так необходимо для постройки более устойчивого туристического сектора, обеспечивающего широкое и справедливое использование преимуществ туризма, несмотря на сложившуюся эпидемиологическую обстановку в мире.

Туристические компании различных стран мира, которые не прекратили осуществление своей деятельности под влиянием COVID-19 и были настроены на свое развитие, воспользовались временем введенных ограничений в целях ускорения перезагрузки отрасли, проведения диджитализации, запуска цифровых платформ, экологичных решений и изменения подходов $\mathrm{K}$ организации туризма в целом.

Новая экономическая модель туристического бизнеса, которая актуальна в настоящий момент в современном мире, напрямую связана с внедрением во всех сферах туризма цифровых технологий, обеспечивающих поддержание и развитие исследуемой отрасли в такой сложный период для всего мира. Диджитализация обеспечивает не только ускорение процесса осуществления деятельности, но и помогает в координации и партнерстве, что является одной из намеченных тенденций в туризме, посредством проведения различных онлайн-интенсивов, вебинаров и создания платформ [13].

Направленностью на цифровизацию туризма, как составной части национальной экономики, заинтересованы органы власти России, также как и иных стран мирового пространства. В связи с этим проводится множество обучающих и информационных онлайн-мероприятий для туристических операторов.

Например, в России Комитет по туризму города Москвы вместе с туристическим сообществом организовали более 70 отраслевых онлайн-мероприятий, включая антикризис- 
ные вебинары, воркшопы, международные роуд-шоу и телемосты. Пятидневный антикризисный онлайн-интенсив в апреле прослушали более 4000 сотрудников турагентств, отелей и авиакомпаний из России и СНГ, представители региональных администраций и туристических офисов других стран [14].

Такая тенденция наблюдается не только на территории России и стран СНГ, но и в других странах мира. Например, в Греции была создана платформа «Греция из дома» для профессионалов в сфере туризма, предназначенная для обучения цифровым инструментам и улучшения цифровых навыков с помощью сертифицированных онлайн-курсов и вебинаров. Венгерское агентство по туризму вместе с Альянсом туристических ассоциаций Венгрии и Будапештским экономическим университетом создали платформу электронной обучающей Академии туризма для повышения экономической конкурентоспособности туристических малых и средних предприятий [14].

Среди населения в период распространения коронавируса все больше возрастает спрос на онлайн-платформы, использование которых позволит не только построить маршруты туров путем поиска и бронирования билетов, жилья, но и самой туристической программы в месте отдыха. Примером такой онлайн-платформы в России служит сервис RUSSPASS, с помощью которого туристы могут самостоятельно организовать свое путешествие на территории России, при этом учесть каждую деталь, а именно: приобрести билеты на самолет, поезд, различные экскурсии, в музеи и театры, узнать об интересных местах и полезных услугах в режиме «одного окна» [15]. Такой подход к организации туристических поездок для туроператоров выступает, так же как и для самих туристов, удобным и практичным сервисом, потому что общение с клиентом осуществляется посредством онлайн-формата, что значительно сокращает время обслуживания потенциальных туристов, следовательно, повышается производительность компаний, оказывающих услуги в сфере туризма.

Согласно мнению заместителя Мэра Москвы Натальи Сергуниной, в настоящий момент в связи с действием ограничений, введенных во время пандемии новой коронавирусной инфекции COVID-19, сформировался огромный отложенный спрос на путешествия и поездки за границу. Весь этот накопленный спрос необходимо будет компенсировать после снятия всех ограничений на международные поездки. По этой причине среди туроператоров будет высокая конкуренция, которую выдержат только те, кто будет к этому готов, у кого будут выгодные предложения и лучшая инфраструктура, в том числе цифровая. За последние месяцы люди по всему миру привыкли к новому уровню цифрового комфорта, что повысило уровень их требований. Следовательно, компании, оказывающие услуги в сфере туризма, должны сохранять свою конкурентоспособность на рынке путем цифровой адаптации, развития и поддержания технологичных проектов в туристической отрасли [16].

Как своеобразную часть туристической отрасли можно рассматривать гостиничный бизнес, который предоставляет жилье для туроператоров или для самих туристов. Эту часть туризма также коснулась цифровизация во время пандемии, поэтому большинство компаний, осуществляющих размещение туристов, перевели свою организационную и маркетинговую деятельность в онлайн-режим с помощью применения цифровых технологий [17].

Более детально рассмотрим цифровую маркетинговую сферу в туристической отрасли как часть новой экономической модели ведения бизнеса. Маркетинговые коммуникации туроператоров должны быть направлены не только на распространение информации о самой туристической компании и предоставляемых гостиницах, отелях, но и на формирование единого информационного образа в сознании потребителя услуг, который обладает своими ключевыми характеристиками относительно конкурентов в секторе туризма [17].

Использование сети «Интернет» как ключевого канала маркетинга является беспроигрышным вариантом и одним из основных в продвижении туристических услуг. Такая тенденция связана со стабильным ростом числа туристов, которые заранее бронируют номера в отелях и гостиницах на сайтах компаний, работающих в сфере туристического бизнеса. Поэтому важным инструментом цифрового продвижения выступает наличие собственного сайта не только туроператора, но и гостиницы или сети отелей.

От оформления и качества работы сайта зависит количество новых клиентов, которые будут привлечены с помощью его использования. Наличие функционирующих сайтов является 
необходимым условием цифрового продвижения, так как на данный момент более половины туристов и иных потребителей туристических услуг бронируют номера через сайты.

Сайты туристических и гостиничных компаний выступают важнейшим инструментом цифрового пространства, однако и такой инструмент имеет некоторые недостатки, которые состоят в высокой стоимости его создания, необходимости круглосуточной поддержки связи с клиентами посредством сайта, правильного его оформления [18].

SEO-оптимизация представляет создание семантического ядра сайта, что предполагает наличие главного ключевого слова и связанных с ним иных ключевых слов, которые содействуют нахождению сайтов гостиниц через конкретные поисковые запросы [19]. Недостатком такого инструмента является необходимость постоянного обновления и актуализации информации, а также SEO будет функционировать лишь при соответствии сайта туроператора с поисковым запросом, также недостатком выступает достаточно долгая окупаемость вложенных средств в данное направление продвижения (до 6 месяцев).

Наиболее приемлемым вариантом для цифрового продвижения выступает использование крауд-маркетинга, представляющего собой регулярное упоминание названия туристической организации на различных информационных интернет-ресурсах. Большим преимуществом являются ненавязчивость для пользователей, привлечение внимания заинтересованных клиентов, которые организуют самостоятельные путешествия [9].

Самым эффективным инструментом цифрового продвижения (это касается не только туриндустрии) на данный момент является использование социальных сетей, создание и ведение страниц конкретной компании.

Сейчас существует множество различных социальных сетей, ориентированных на разную возрастную категорию, поэтому необходимо учитывать этот фактор и проводить анализ це- левой аудитории на определенном социальном сайте.

Наиболее востребованными и популярными социальными сетями являются Instagram и TikTok. При условии правильно выстроенной тактики ведения страницы туристичсекой компании в Instagram, существует высокая вероятность быстрой реакции потенциальных клиентов, которые перейдут в категорию реальных. Указанная социальная сеть имеет множество рекламных инструментов для ведения бизнеса, в том числе и в сфере туризма, среди которых продвижение публикаций, настройка рекламы, использование хештегов [20].

Цифровое продвижение для развития устойчивости туристического бизнеса выступает важной категорией в системе функционирования представленной деятельности, так как во время действия определенных ограничений туристы, как правило, в онлайн-режиме подбирают и рассматривают потенциальных туроператоров, к которым бы хотели обратиться после снижения уровня заболеваемости новой коронавирусной инфекцией COVID-19.

Таким образом, проведя исследование, можно сказать, что пандемия COVID-19 принесла в нашу жизнь множество проблем, связанных не только со сферой здравоохранения, но и большое негативное влияние было оказано на мировую экономику, особенно пострадала туристическая отрасль, где за период 2019-2020 гг. наблюдаются большие потери доходов. Однако время распространения новой коронавирусной инфекции подвигло множество туристических компаний использовать новые модели ведения своего бизнеса, одним из главных элементов которых выступает цифровизация отдельно каждой туристической компании, а также всей отрасли туризма в целом. Использование цифровых технологий в области туризма поддерживается также со стороны государства, что создает дополнительную безопасность их применения и повышения своей конкурентоспособности в такой сложной эпидемиологической обстановке.

\section{Библиографический список}

1. РБК: Анализ российского рынка туристских услуг: итоги 2019-2020 гг., прогноз до 2024 г. [Электронный ресурс]. - Режим доступа: https://marketing.rbc.ru/articles/12440/ (дата обращения: 16.11.2021).

2. Общество и пандемия: опыт и уроки борьбы с COVID-19 в России [Электронный ресурс]. - Москва: 2020. 744 с. - Режим доступа: https://publications.hse.ru/mirror/pubs/share/direct/414121642.pdf (дата обращения: 16.11.2021). 
3. РБК: Как индустрии выживают в период пандемии: туризм. [Электронный ресурс]. - Режим доступа: https://style.rbc.ru/impressions/5e8c609a9a79477c5afb2336 (дата обращения: 16.11.2021).

4. Всемирная туристская организация UNWTO: Руководство восстановления туризма [Электронный ресурс]. Режим доступа: https://www.unwto.org/tourism-covid-19 (дата обращения: 16.11.2021).

5. Федеральная служба государственной статистики [Электронный ресурс]. - Режим доступа: https://rosstat. gov.ru/ (дата обращения: 16.11.2021).

6. Федеральное агентство по туризму [Электронный ресурс]. - Режим доступа: https://tourism.gov.ru/ (дата обращения: 18.11.2021).

7. Единый федеральный реестр туроператоров [Электронный ресурс]. - Режим доступа: https://tourism.gov. ru/operators/ (дата обращения: 18.11.2021).

8. Перечень мер в связи с коронавирусом (COVID-19), 2021. [Электронный ресурс]. - Режим доступа: http:// www.consultant.ru/document/cons_doc_LAW_348585/ (дата обращения: 16.11.2021).

9. Сагынбекова А.С. Цифровая экономика: понятия, перспективы, тенденции развития // Международный научно-технический журнал «Теория. Практика. Инновации» (электронный журнал). - № 4 (28). - 2018. [Электронный ресурс]. - Режим доступа: http://www.tpinauka.ru/2018/04/Sagynbekova.pdf (дата обращения 16.11.2021).

10. Доклад ОOH «COVID-19 и трансформация туризма» [Электронный ресурс]. - Режим доступа: https://www. unwto.org/tourism-covid-19 (дата обращения: 18.11.2021).

11. Министерство цифрового развития, связи и массовых коммуникаций Российской Федерации: официальный сайт // Национальная программа «Цифровая экономика Российской Федерации», утвержденная протоколом от 4 июня 2019 г. - № 7. [Электронный ресурс]. - Режим доступа: https://digital.gov.ru/ru/activity/ directions/858/ (дата обращения: 16.11.2021).

12. Швец И. Ю. Глобальное и локальное влияние COVID-19 на сферу туризма // Экономический вестник ИПУ PAH, 2021. - № 2 .

13. Курочкина А. А., Лящук А. С., Смирнова С. А. Digital-маркетинг в гостиничном бизнесе // Бизнес. Образование. Экономика: Междунар. науч.-практ. конф. М: Институт бизнеса БГУ, 2020. - Ч. 1. - С. 361-366.

14. Ведомости\&: Как коронавирус меняет мировую туриндустрию, 2020. [Электронный ресурс]. - Режим доступа: https://www.vedomosti.ru/partner/articles/2020/12/20/851707-antivirus-puteshestvii (дата обращения: 20.11.2021).

15. Агентство инноваций города Москвы: официальный сайт // [Электронный ресурс]. - Режим доступа: https://innoagency.ru/ru/ (дата обращения: 20.11.2021).

16. Официальный сайт Мэра Москвы. [Электронный ресурс]. - Режим доступа: https://www.mos.ru/news/ item/80068073/ (дата обращения: 20.11.2021).

17. Ойнер О.К. Удовлетворенность потребителя. Эмпирические исследования и практика измерения: монография / под ред. О.К. Ойнер. - Москва: ИНФРА-М, 2020. - 220 с. - Режим доступа: https://znanium.com/ catalog/product/1094555 (дата обращения: 20.11.2021).

18. Николенко П.Г. Гостиничная индустрия: учебник и практикум для среднего профессионального образования / П. Г. Николенко, Е. А. Шамин, Ю. С. Клюева. - Москва: Издательство Юрайт, 2019. - 449 с.

19. Жильцова О. Н. Интернет-маркетинг: учебник для вузов / О. Н. Жильцова [и др.]. - 2-е изд., перераб. и доп. М.: Изд. Юрайт, 2019. - 301 с. - Режим доступа: https://urait.ru/bcode/432128 (дата обращения: 20.11.2021).

20. Куликов О.А. Пандемия коронавируса как фактор интенсификации развития и внедрения цифровых технологий // Известия Саратовского университета. Новая серия. Серия Экономика. Управление. Право, 2020. - Т.20, вып. 4. - Режим доступа: https://cyberleninka.ru/article/n/pandemiya-koronavirusa-kak-faktorintensifikatsii-razvitiya-i-vnedreniya-tsifrovyh-tehnologiy (дата обращения: 20.11.2021). 